\title{
Reflets
}

Revue ontaroise d'intervention sociale et communautaire

\section{À la recherche d'un service en français dans le Nord-ouest de l'Ontario}

\section{Denyse Boulanger Culligan}

Volume 2, numéro 1, printemps 1996

Contrer la violence subie par les femmes et les enfants en milieu familial

URI : https://id.erudit.org/iderudit/026114ar

DOI : https://doi.org/10.7202/026114ar

Aller au sommaire du numéro

Éditeur(s)

Reflets : Revue ontaroise d'intervention sociale et communautaire

ISSN

1203-4576 (imprimé)

1712-8498 (numérique)

Découvrir la revue

Citer cet article

Boulanger Culligan, D. (1996). À la recherche d'un service en français dans le Nord-ouest de l'Ontario. Reflets, 2(1), 169-171. https://doi.org/10.7202/026114ar

Tous droits réservés (C) Reflets : Revue ontaroise d'intervention sociale et communautaire, 1996
Ce document est protégé par la loi sur le droit d'auteur. L'utilisation des services d'Érudit (y compris la reproduction) est assujettie à sa politique d'utilisation que vous pouvez consulter en ligne.

https://apropos.erudit.org/fr/usagers/politique-dutilisation/ 


\section{À la recherche d'un service en français dans le Nord-ouest de l'Ontario}

\section{D enyse B oulanger $C$ ulligan}

C oordonnatrice, programme de prévention de la violence $C$ omité des femmes francophones du $\mathrm{N}$ ord-ouest de l'O ntario (CF F 00 ), T hunder B ay

D ans cet article, nous décrivons brièvement les démarches d'un groupe communautaire en vue d'obtenir un service en français dans notre coin de la province, le $\mathrm{N}$ ord-ouest, pour les femmes victimes de violence ou d'agression à caractère sexuel.

Thunder Bay dessert les communautés de la région du $\mathrm{N}$ ordouest désignées dansla Loi sur les services en français. C ependant, cette ville s'étant déclarée unilingue en 1990, les services en français sont quasi inexistants dans maints domaines, tout particulièrement dans celui de la santé et des services sociaux. À ce sujet, $R$ éjean $N$ adeau, coordonnateur provincial des services en français du ministère des Services sociaux et communautaires disait: «Les services en français dans le $\mathrm{N}$ ord-O uest, c'est la pauvreté totale».

C'est dans ce contexte qu'au début des années 80 , quelques pionnières ont mis en oeuvre des projets d'éducation et de prévention contre la violence faite aux femmes et aux enfants. En 1992, des femmes représentant les huit régions désignées du $\mathrm{N}$ ord-ouest, ainsi que la ville de Thunder Bay, se sont rassemblées pour former le Comité des femmes francophones du N ordouest de l'O ntario (CFFnoo). Suivant les traces de leurs précurseures, le CFFN 00 souhaite que lesfemmes du N ord-ouest 
soient représentées et reconnues au sein de leurs communautés et des groupements provinciaux.

En mai 1994, le cFfn o o publiait une étude sur les besoins des femmes francophones du N ord-ouest en matière de violence contre les femmes et d'agression à caractère sexuel. C ette étude comportait certaines recommandations, entre autres d'avoir une ligne téléphonique (sans frais) d'aide, d'appui et d'écoute pour les femmes francophones victimes de violence ou d'agression à caractère sexuel de la région du N ord-ouest. C ette recommandation répondait à un réel besoin, car la ligne de l'organisation s.o.s. Femmes deToronto n'a jamais pu être accessible depuis dans le N ord-ouest.

L'étude du CFFN o o montrait aussi les difficultés éprouvées par les femmes francophones de ces communautés, lorsqu'elles choisissent de briser le silence et de dénoncer la violence ou l'abus sexuel qu'elles subissent. C omme lesfemmes du N ord- ouest sont dans l'impossibilité d'aller chercher de l'aide ou de l'appui, les services n'existant pas dans leur communauté, un service téléphonique sans frais serait la manière la plus économique et la plus efficace de rejoindre les femmes ou la population et d'offrir un service en français.

Le CFFN 00 a donc décidé de poursuivre la solution proposée par les femmes du N ord- ouest. En septembre 1994, les membres du CFFN 00 ont organisé une campagne de pression politique qui a rejoint tous les paliers gouvernementaux, et une bonne partie de la population de l'O ntario. En janvier 1995, une rencontre entre les différents ministères impliqués et la CFFN 00 a eu lieu à Thunder Bay. Les membres du CFFN 00 croyaient vraiment que les besoins flagrants des femmes allaient être reconnus. Hélas, l'argument «nous n'avons pas d'argent calculé sur une année» était à l'ordre du jour. Toutefois, la position du ministère de la Santé laissait une porte ouverte. Si le CFFNoo était d'accord, il pouvait travailler en collaboration avec un centre de soins hospitaliers pouvant desservir les victimes d'agression sexuelle dans un hôpital local, et inclure une ligne 1-800 au sein de ce centre. 
A près maintes discussions, les membres du CFFN 00 ont décidé de poursuivre cette possibilité, tout en sachant à l'avance les difficultés à surmonter pour s'intégrer à un tel programme. M ieux valait faire face à ces difficultés que de s'avouer vaincues et de dire aux femmes du N ord-ouest que le cFfn o o les oubliait.

Depuis avril 1995, le cFFn 00 s'est mis à l'oeuvre, même si à I'heure actuelle, et compte tenu des nouvelles coupures budgétaires faites par le gouvernement $\mathrm{H}$ arris, il se pourrait fort bien que l'on supprime les $C$ entres de soins hospitaliers pour les femmes victimes d'agressions à caractère sexuel. Les besoins des femmes francophones du $\mathrm{N}$ ord- ouest de I'O ntario sont toujours aussi importants. Le CFFNoo est toujours à la recherche d'un service en français. Du fait que le gouvernement abolit les services aux femmes victimes de violence ou d'agression à caractère sexuel, aurons-nous à faire une campagne financière auprès de la population ontarienne afin de pouvoir offrir un service d'urgence en français, ou serons- nous inclues ou exclues dans la restructuration des services qui s'effectue présentement au sein de certains ministères?

\section{Bibliographie}

COMITÉ DES FEMMES FRANCOPHONES DU NORD-OUEST DE L'ONTARIO et ACCUEIL FRAN COPHONE DE THUNDER BAY (mai 1994). É tude de besoins pour les femmes francophones du $\mathrm{N}$ ord- $\mathrm{O}$ uest de l' $\mathrm{O}$ ntario au sujet de la violence faite aux femmes et de l'agression à caradère sexuel, Thunder Bay, Comité desfemmesfrancophones du $\mathrm{N}$ ord- ouest de l'O ntario et Accueil francophone deThunder Bay. 